Historic, Archive Document

Do not assume content reflects current scientific knowledge, policies, or practices. 



\section{OCT 91905}

\section{Bulletin No. 7}

1905

COTTON GROWING ON SANDY UPLAND SOILS

PLAND SOILS

Tuskegee Normal and Industrial Institute

\section{EXPERIMENT STATION}

Tuskegee Institute, Alabama

Geo. W. Carver 


\section{THE TUSKEGEE EXPERIMENT STATION}

\section{Board of Regents}

President, Charles Coleman Thatch.............. How. R. R. Poole.................... Montgomery, Ala

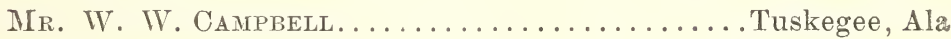
Mr. Charles W. Hare.................................... Ala Mr. A. J. Wilborn.....................Tuskegee, Ala Mr. Booker T. Washington . ........ Tuskegee Institute, Ala

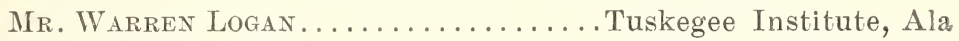

\section{Station Staff}

G. W. Carver, M. S. Ag...................... Director

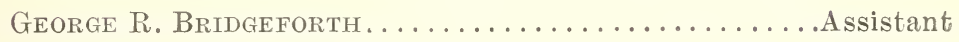
Perry C. Parks......................... Sarm Superintendent

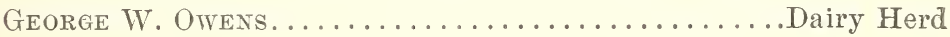

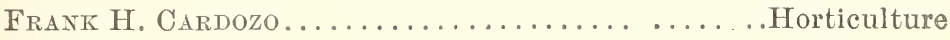
J. B. Brown ........................... Truck Garden

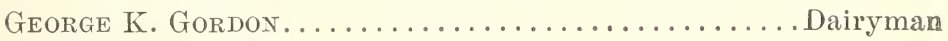

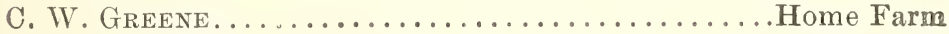

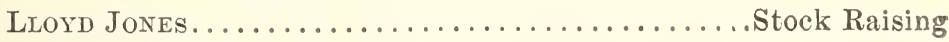





\section{The Tuskegee}

\section{Agricultural Experiment Station}

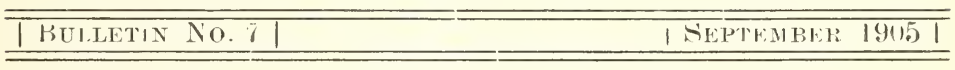

COTTON GROWING ON SANDY UPLAND SOILS

G. W. Carver, M. S., Agr. Director

This bulletin, in some degree is a continuation of $x_{0} \quad 6$, on Soil Building, and emphasizes rather emphatically the possibilities of such soils in the production of cotton.

We have maintained that every acre of land in Alabama capable of being grown in cotton, could and should be made to produce at least one bale to the acre. The experiment further shows the value of selecting good seed and of a variety best suited to the locality in which it is to be grown.

\section{THE SOIL AND ITS PREPARATION}

The soil upon which these experiments were made is light, sandy, and constitutes the original poorest section of the experimental field.

Cow peas were growll upon these plots during the summer of 1903; the dry peas picked and the stubble turned under with a Boy Dixie turning plow, by going twice in the same furrow. September 20, one hundred pounds each of acid phosphate and Muriate of potash was mixed with ten tons of barn yard manure and muck from the swamp, mixed half and half, and harrowed in thoroughly with a spring tooth harrow. Wheat, oats, rye, vetch, etc., were sown for grazing. It made an excellent growth; it was grazed off, allowed to get two or three inches high and plowed under.

A very low bed was thrown up, opened, and the fertilizer (which consisted of the same kinds and quantity used for the small grain) was put directly into the furrow and the seed planted upon it, covering the same with a scooter. The seed were all planted April 22, and jertilized as per above, unless otherwise stated. 
VARIETIES TESTED

\begin{tabular}{|c|c|c|c|c|c|c|c|c|}
\hline $\begin{array}{l}\text { Name of } \\
\text { Variety }\end{array}$ & $\begin{array}{c}\text { Seed } \\
\text { Cotton } \\
\text { in } \\
\text { Pounds }\end{array}$ & $\begin{array}{l}\text { Lint } \\
\text { Cotton } \\
\text { in } \\
\text { Pounds }\end{array}$ & $\begin{array}{l}\text { Seed in } \\
\text { Pounds, } \\
\text { Rcund } \\
\text { Numbers }\end{array}$ & $\begin{array}{l}\text { Bushels } \\
\text { of Seed }\end{array}$ & $\begin{array}{l}\text { Value of } \\
\text { Lint at } \\
10 \text { cents } \\
\text { Pound }\end{array}$ & $\begin{array}{l}\text { Talue of } \\
\text { Seed at } \\
70 \mathrm{c} \mathrm{Per} \\
100 \mathrm{lbs}\end{array}$ & $\begin{array}{c}\text { Grand } \\
\text { Total }\end{array}$ & $\begin{array}{c}\text { More or } \\
\text { Less than } \\
\text { one bale } \\
\text { per acre }\end{array}$ \\
\hline $\mathrm{K}$ & 1290 & 450 & 840 & $26 \quad 1-4$ & $\$ 4500$ & $\$ 5 \varepsilon 8$ & $\$ 5088$ & * $50 \mathrm{lbs}$ \\
\hline $\begin{array}{l}\text { Kussell } \\
\text { Big Boll }\end{array}$ & 1340 & 470 & 870 & $27 \quad 3-16$ & 4700 & 609 & $530 s$ & $* 30 \mathrm{lbs}$ \\
\hline $\begin{array}{l}\text { Willets } \\
\text { Red Leaf }\end{array}$ & 1290 & 400 & 890 & $27 \quad 13-16$ & 4000 & 622 & 3 & *100 ibs \\
\hline $\begin{array}{l}\text { Berry } \\
\text { Big Boll } \\
\text { Peterkin } \\
\text { Cross Land } \\
\text { Culpepper }\end{array}$ & $\begin{array}{r}1600 \\
750 \\
1250 \\
1100\end{array}$ & $\begin{array}{l}520 \\
280 \\
480 \\
390\end{array}$ & $\begin{array}{r}1080 \\
470 \\
770 \\
710\end{array}$ & $\left\{\begin{array}{cc}33 & 3-4 \\
14 & 11-16 \\
24 & 1-16 \\
22 & 3-16\end{array}\right.$ & $\begin{array}{ll}52 & 00 \\
28 & 00 \\
48 & 00 \\
39 & 00\end{array}$ & $\begin{array}{ll}7 & 56 \\
3 & 29 \\
5 & 39 \\
4 & 97\end{array}$ & $\begin{array}{ll}59 & 56 \\
31 & 29 \\
53 & 39 \\
43 & 97\end{array}$ & $\begin{array}{l}+20 \mathrm{lbs} \\
* 220 \mathrm{lbs} \\
* 20 \mathrm{lbs} \\
* 110 \mathrm{lbs}\end{array}$ \\
\hline $\begin{array}{l}\text { Excelsior } \\
\text { Prolific }\end{array}$ & 1240 & 420 & 820 & $25 \quad 5-16$ & 4200 & 574 & 4774 & * $\varepsilon 0 \mathrm{lbs}$ \\
\hline ar $m$ coun. & 970 & 350 & 620 & $19 \quad 3-8$ & 3500 & 434 & 3934 & $* 150 \mathrm{lbs}$ \\
\hline
\end{tabular}

NotE-* equals less than a bale; $\dagger$ equals more than a bale

The following varieties were tested and the yield tabulated:

Yield of plots per acre, as shown in the above table, which is largely self explanatory.

In justice to Willet's Red Leaf it should be stated that it was not planted until the 17 th of May, and had to withstand two very unfortunate seasons during the critical period of its growth. First was a wet one just as the middle crop began to form which caused considerabie shedding of bolls. This was immediately followed by nearly nine weeks of drought; whish arrested the top crop.

DESCRIPTION OF VARIETIES

KING

Was rather slow in germinating (probably due to the dry period after planting) but came up well and made a rapid growth. The plants are short, stalky and much branched; the bolls are rather small, seed medium in size and thickly covered with a gray down frequently shading into brown. It opened the earliest of all the varieties tested.

RUSSELL BIG BOLL

Or the Big Green Seed as it is frequently called, needs but little description. The bolls are very large, seed covered with a green down. It especially likes a deep rich soil and responds very satisfactory to heavy applications of manure.

WILLET'S RED LEAF

This variety is distinct from all others, as the whole plant throughout-leaves, stems and squares-are a deep, heavy, reddish brown, even the flowers are tipped with it. It is a good grower and holds its foliage well. 
BERRY BIG BOLL

This distinctly belongs to the Big Boll group, having a large, well fuzzed grayish seed. It is a vigorous grower, fruiting well and continuous; limbs, long and spreading. It is also decidedly partial to rich damp land, but adjusts itself to light soils very well as the yield indicates.

\section{PETERKIN}

Too old to need any description. For some reason this made the poorest growth of all the varieties, but was heavily fruited. Almost throughout the entire county it gave a poor yield, which, according to Auburn and other experiment stations is rather remarkably low, as the results with them were much better.

\section{CROSSLAND}

This variety has rather small bolls and seed, the latter largely free from down. The plants were only medium in growth but heavily fruited out to the ends of the spreading branches. I am favorably impressed with it.

\section{CULPEPPER}

I should class this with the Big Boll varieties, having both large bolls and seed. It grew off well, fruited heavily, but shed its bolls badly during the excessive wet weather.

\section{EXCELSIOR PROLIFIC}

Seed having but little down. The bolls are borne in clusters so thick that they are almost crowded off. It is a fine grower, vigorous and healthy, but the excessive rains seemed to rot the bolls, largely due to them being so close together that they did not have time to dry cut between showers.

\section{DISEASES}

During the entire season all the varieties were remarkably free from diseases of any kind.

\section{COTTON WILT}

(Neocosmosporo Vasinfecta (Atk). E. F. Smith.)

Was observed only on a few plants of Berry Big Boll. This disease was very troublesome in an adjoining field.

ANTHRACNOSE OF THE STEM

\section{(Colletotrichum Gossyppi South)}

This disease ordinarily confines itself to the bolls; appearing first upon the boll in the form of a dark sunken spot which afterwards becomes a redish brown or pink. It occasionally attacks the stems ard leaves. A few infected bolls were found, but upon the whole it was quite free from this trouble. 


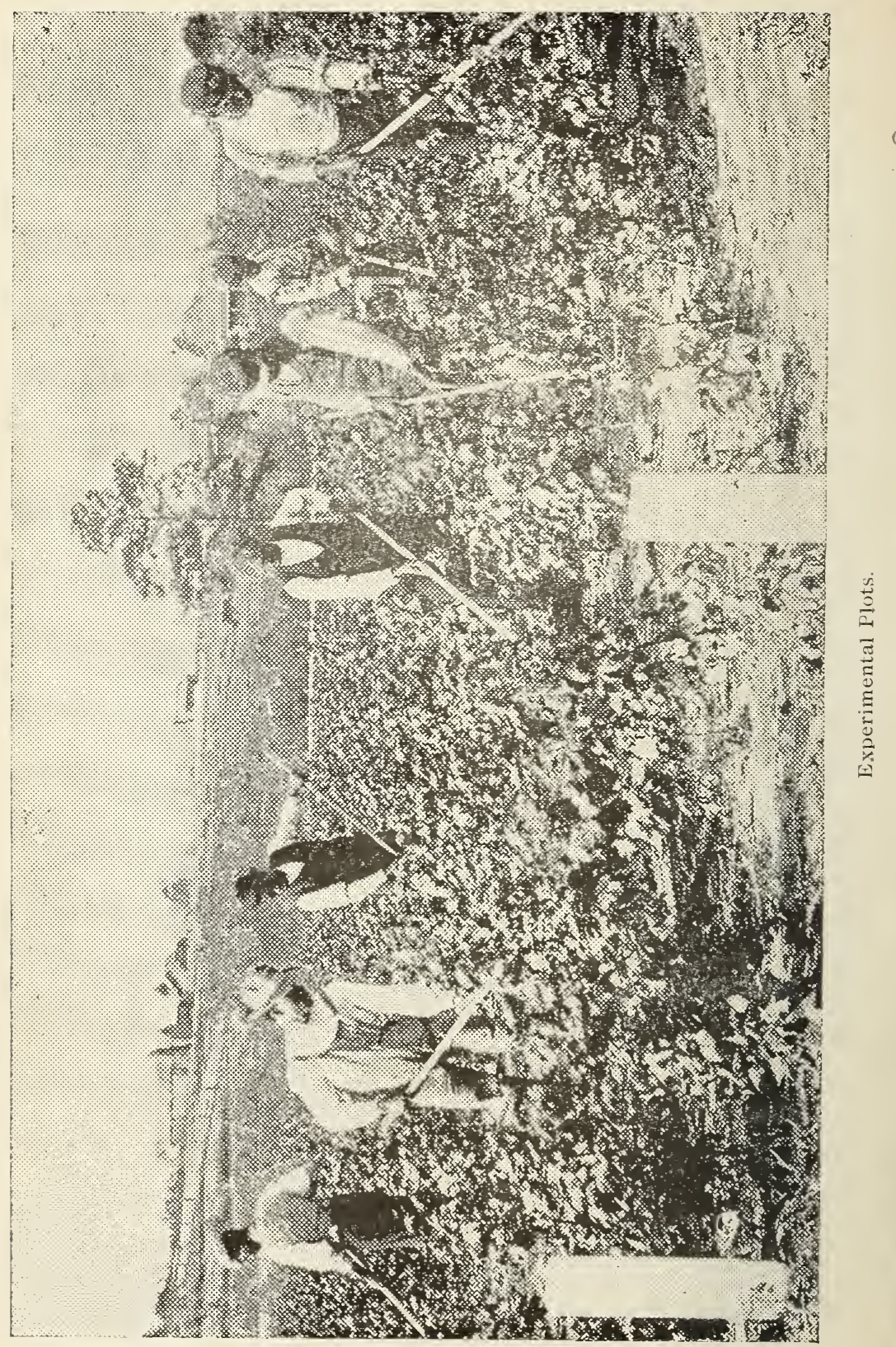




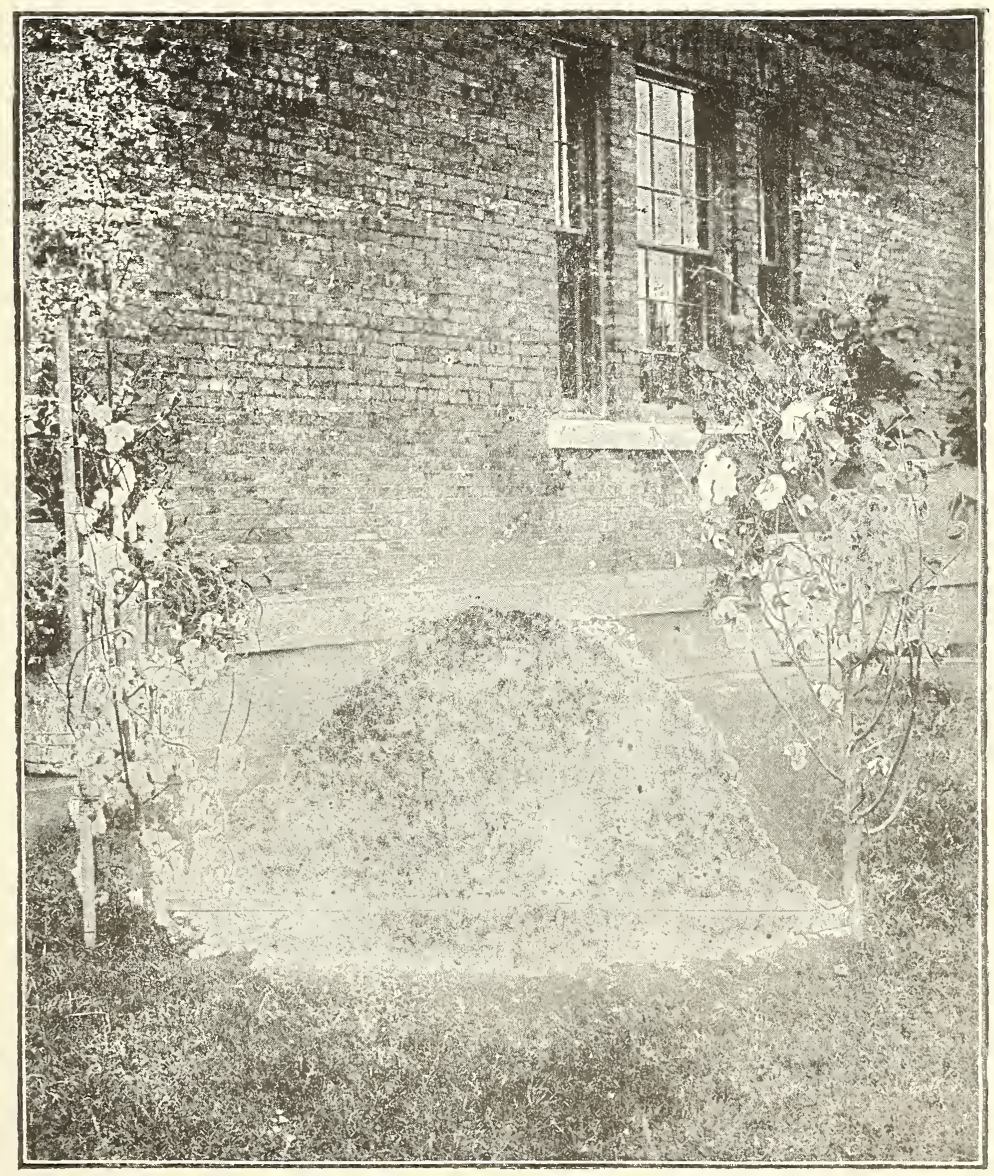

520 Pounds of lint per acre. 
MILDEW

(Ramularia areola Atk)

This disease is very troublesome in some sections, appearing in August and lasting until frost. The leaves are covered over more or less with powdery, frosty looking patches, which in course of time defoliates the plant. Close observation failed to reveal the slightest trace of this disease.

\section{RUST}

Which is a misnomer, is due to several species of fungi, the description of which is too technical to be of either interest or value here. They attack the plant in spots (mainly the leaves.) and frequently completely defoliate it. The bolls and stems are by no means exempt. While some of these diseases could be found in all of the varieties, they could not be considered troublesome. The same can be said of the root diseases. All varieties were remarkably free except a bushel of mixed seed which were purchased from the country. Under the same conditions as to preparation of land, fertilizing, cultivation, etc. This plot fell 150 pounds short of a 500 pound bale of lint. The plants lacked in vitality from the first, and did not thoroughly recover. Root rot, shedding of bolls, and various fungus diseases were observed on this plot.

In addition to the above an experiment was made to test the value of clean cultivation and frequent shallow plowing during very dry periods. Two plots were chosen along-side of each other, prepared, fertilized, and planted exactly alike and on the same day and with the same variety of seed. Plot 1 , received four plowings with a five tooth cultivator-one every nine days. Before the crop matured it became foul with weeds and grass. During the time the plowing was done a drought was on, and only .50 (one hundredths) of an inch of water fell during the entire time. The sandy portion dried out quickly, while the clay baked, cracked open, and became very siard.

Just as the crop began to mature, frequent showers fell. The various fungus diseases soon defoliated most of the plants and completely cut off the top crop. The weeds and grass grew and almost hid the cotton in places. The yield was only 152 pounds of lint to the acre.

Plot 2 was plowed with the same cultivator every five days, forming a perfect dust mulch. The plot was kept free from weeds and grass, and the plants were more than double the size of plot 1 . 
This plot was not seriously injured by fungus diseases; it gave a good top crop and continued to grow and flower until frost, and yielded 456 pounds of lint to the acre. In connection with all these experiments it is important to state that the cultivator was used almost wholly. The sweep was used to lay the crop by as the plants had grown too large for the cultivator By the use of this labor saving machinery, the cost of cultivation was reduced quite one-half and the work done most effectually.

\section{CONCLUSION}

Since the annual yield per acre of lint cotton in Alabama varies from 110 to 140 pounds, it is clear that in the first case, we are producing 15 pounds less, and the latter, 21 pounds above one-fourth the amount we should.

As a result of four years of experimentation with practically the same results, we feel quite safe to conclude:

1-That it pays to prepare the land, both deep and thorough before planting.

2-That swamp muck, leaves, etc., are a very essential and valuable addition to our commercial fertilizers.

3-That good, clean seed of a standard variety is murh better than a miscellaneous mixture, saved without reference to variety, vitality, or freedom from fungus disea-es.

4-That clean cultivation pays from every point of view.

5-That if the ground is prepared well, labor saving machinery can be used to advantage.

6-That our poorest sandy soils can be economically made to produce a full 500 pound bale of lint to the acre. 


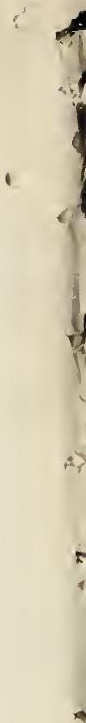

